\title{
El artey la heterogeneidad histórico estructural en la obra de Aníbal Quijano
}

\author{
Carolina 0rtiz Fernández \\ Universidad Nacional Mayor de San Marcos \\ cortizf@unmsm.edu.pe
}

\section{RESUMEN}

En esta ocasión, exploro de manera introductoria las categorías heterogeneidad histórico estructural y la importancia del arte en la obra de Aníbal Quijano en diálogo con algunos pasajes de su biografía.

PALABRAS CLAVE: heterogeneidad histórico estructural, tiempo, arte, horizonte de sentido

Talking with Anibal Quijanos work. Art, historical structural heterogeneity, time and the horizon of meaning.

\section{ABSTRACT}

On this occasion, I make an approach to his reflection on the structural historical heteroge- neity category, the time and importance of art in his work in dialogue with some passages of Quijano's biography.

KEYWORDS: historical structural heterogeneity, the time, art, horizon of meaning 
a obra de Aníbal Quijano es prolífica y diversa y está por explorar, aunque existe una primera aproximación de Danilo Asís Clímaco en el prólogo de una antología organizada por él (2014), en la que ha logrado reunir un conjunto de textos que estaban dispersos.

Como bien lo precisan Pablo Gentili y Karina Bidaseca, cuando Quijano era entrevistado solía responder que no tenía el hábito de la sistematización de la escritura, y que por eso prefería "escribir al viento". Frase que podría tener un sentido cercano a "solía escribir con su dedo grande en el aire", verso de uno de los poemas de nuestro poeta mayor César Vallejo en España aparta de mi este Cáliz, y alude a esculpir la palabra en el aire, hacerla sentir y volar libre con vida propia: "Papel de viento pasa”, dándole a la escritura un sentido en movimiento, de no fijeza, de oralidad ajeno a toda rigidez, porque la escritura como la oralidad, a decir de lain Chambers (1994) es una constante travesía que cruza los límites entre acontecimiento y narración, entre autoridad y dispersión, entre el pretexto anónimo y la inscripción textual. Los saberes como los humanos que los sistematizan y recrean son móviles, migran constantemente. Son formas discontinuas no establecidas para siempre, lo cual no niega las continuidades que también arraigan.

En esta ocasión evocaré algunos pasajes que expresan mi primera aproximación a modo de semblanza del maestro y amigo Aníbal Quijano, seguidamente exploraré de manera introductoria las categorías heterogeneidad histórico estructural y la importancia del arte en la obra de Aníbal Quijano en diálogo con algunos pasajes de su biografía.

En mi época estudiantil en los 80, tuve en San Marcos a queridos maestros que recuerdo con mucha gratitud, entre ellos a Julio Cotler, César Germaná, Aníbal Quijano. Entre toques de queda, apagones, coches bomba, conflicto armado, las calles y parques sitiados por las fuerzas militares y policiales, la crisis económica y la incertidumbre de si volvíamos a casa con vida, la vida universitaria como todo se tornó muy accidentada. Recuerdo mi asistencia a una de sus clases y la ciudad universitaria sanmarquina totalmente oscura, solo se percibía la luz de una vela encendida como en la mayoría de casas y barrios en tiempos de absoluta oscuridad y violencia política que desangró al país. Mientras la mayoría, en cada sorpresivo apagón se retiraba, Quijano y sus estudiantes nos quedábamos continuando la clase con una vela encendida. Era su manera de responder, la suya y la del grupo de estudiantes que asistíamos, al terrorismo de Sendero Luminoso y del Estado peruano. Hasta que finalmente, cuando el ejército y el fujimorismo ocupó la universidad, Quijano renunció a ella. 
En 1990, decidí trabajar mi tesis referente a la problemática indígena y de las mujeres a través de la vida y obra de Clorinda Matto de Turner que fue sustentada finalmente en 1993. Me interesaba comprender qué había ocurrido hacía aproximadamente un centenar de años en relación a esa problemática y qué venía ocurriendo en el presente de aquel entonces, a inicios de los 90 del siglo XX desde la visión de las mujeres, hijas de inmigrantes serranos, en mi caso hija de inmigrantes ancashinos, ya que tanto en los barrios y escuelas en los que viví, estudié y trabajé sentí que estaban latentes las interdependencias de las relaciones de dominación socioeconómica con las de género y étnico racializadas y porque tanto la población indígena y las mujeres fueron las más afectadas durante la violencia política que asoló al país entre 1980 y 1992. Y porque en el Perú, las mujeres carecíamos de una genealogía intelectual.

Interesarse en San Marcos sobre estas cuestiones en los noventa no era bien recibido, porque toda investigación que no se circunscribía exclusivamente a la temática y clasificación socioeconómica, a lo que se ha denominado "clase social" era duramente criticada y combatida.

Dos maestros comprendieron y apoyaron mi inquietud César Germaná y Aníbal Quijano. Fuera de la Escuela de Sociología, me reconfortó el apoyo de Manuel Burga, Antonio Cornejo Polar y Miguel Ángel Huamán. En esa época en la Escuela de Sociología no tuvimos la suerte de contar con maestras.

En uno de mis borradores de trabajo en 1991, Quijano subrayó "la alegre cabaña de los indios", frase de Matto de Turner en la que destacaba que su niñez transcurrió jugando y compartiendo en la casa paterna pero sobretodo en aquel lugar que trascendía querencia y afecto y de la que bebió y aprendió la lengua y la cultura quechua. Hoy asocio su interés a que él también había transcurrido su infancia de manera semejante en Yanama, lugar donde nació.

Continué mis pesquisas sobre lo indicado en el posgrado en Quito y Lima entre 1995-1997 y 1998-2003, años de irrupción de los masivos y vitalísimos movimientos indígenas en Ecuador y en América Latina. Compartí con el maestro Quijano, mis primeras reflexiones sobre ellos, sobre la producción escrita por mujeres, las y los intelectuales "indígenas" $y$ "negros" que se apropiaban creativamente del poder de la palabra escrita y del escenario público en las que el cuerpo y la "Naturaleza", la acción y el discurso forma parte de poéticas y episteme invisibilizados. Si bien no fueron numerosas, fueron conversaciones y discusiones de gran aprendizaje, que se mantuvieron a partir de esas temáticas, involucrados además en los movimientos de la sociedad. Le sorprendía que el cuerpo fuese el punto de partida en la poesía y la reflexión creativa de las mujeres. 
Aníbal Quijano arriba al mundo en un período muy significativo, de grandes movimientos sociales y culturales, de resistencia al "oncenio" dictatorial, corrupto y populista de Augusto B. Leguía y a la crisis mundial de 1929 que se sintió intensamente y afectó a las y los trabajadores por la escasez de los artículos de primera necesidad y el alza del costo de vida. En los años 20 del siglo XX, surgieron dos históricos partidos políticos, la Alianza Popular Revolucionaria Americana (APRA) fundada en México el 7 de mayo de 1924 por Víctor Raúl Haya de la Torre y en 1928 el Partido Socialista del Perú fundado por José Carlos Mariátegui, quien a su vez participó en la creación de la Central General de Trabajadores del Perú (CGTP) y fundó la revista Amauta, una de las más importantes del Perú y América Latina con resonancia continental, en la que se promovió el debate político y dio gran importancia al terreno cultural sin menospreciar el campo económico. Fue un período excepcional en el que surgieron las voces de Magda Portal, César Vallejo, Oquendo de Amat, José Sabogal, Julia Codesido, López Albújar, Dora Mayer, Ángela Ramos.

Quijano nace en Yanama, en 1930, en la provincia de Yungay, en el bello Callejón de Huaylas, cerca al nevado de Huascarán y la laguna de Llanganuco. Su niñez y adolescencia estuvo marcada por el territorio, la cordillera de los Andes y su atmósfera sociocultural y emocional, aprendió el quechua de la región. Yanama, viene de yana, que en quechua ancashino significa negro.

En una entrevista realizada por Eduardo Arroyo (2017), precisa que su padre fue educador y que para completar sus estudios de primaria y de secundaria tuvieron que residir en la ciudad de Yungay, en las vacaciones retornaban a Yanama. Recuerda a Yungay como la ciudad más hermosa de todas las ciudades del Callejón de Huaylas. En esta ciudad transcurrió:

(...) la mayor parte de mis años de niño y de adolescente. Esa ciudad ya no existe. Fue sepultada por un alud producido por el desprendimiento de una cornisa del Huascarán durante el terremoto de 1970. Por eso, cuando me preguntan de dónde soy, respondo que soy de todas partes, porque la ciudad en que viví ya no existe. Por lo tanto puedo ser de todas partes. Yungay (...) Tenía una campiña colorida y fértil. Desde la ciudad se divisaba el Huascarán, como una gran ave de nieve con las alas desplegadas. En agosto, hacia las cinco de la tarde, una aureola entre rosada y dorada jugaba en esas alas. (2017)

Cuando tuvo que dejar Yungay, por las ansias de conocer otros aires y lugares, al igual que la mayoría de inmigrantes a la capital del país, conoció las penurias de 
serlo cuando decidió estudiar en la Universidad Nacional Mayor de San Marcos. Esta experiencia vital, fue decisiva en su reflexión sobre los engranajes entre los procesos de dominación y explotación y la cultura a través de uno de sus primeros trabajos referente a"La emergencia del grupo cholo y sus implicaciones en la sociedad peruana" de 1964 y posteriormente sus pesquisas y propuestas conceptuales referentes a marginalidad, polo marginal de la economía y la "raza" como clasificación y relación social de dominación, opresión y explotación y, desde su visión, el principal componente del patrón global de poder.

Quijano ingresa a San Marcos en 1948, con el ánimo de estudiar medicina, pero finalmente se matricula en derecho y luego en historia, asume una concepción crítica y transdisciplinaria, en tanto sus indagaciones y hallazgos no se circunscriben a una sola disciplina. Continuó estudios de posgrado en la Facultad Latinoamericana de Ciencias Sociales (FLACSO) de Chile.

En su primera publicación de 1956 dedicada al Amauta con el título: José Carlos Mariátegui, ensayos escogidos, expresa su reconocimiento y admiración a su vida y obra, que renueva veintitrés años después en el prólogo a la primera edición de los 7 ensayos de interpretación de la realidad peruana publicado por la Biblioteca Ayacucho (1979). Destaca la adhesión de Mariátegui a la revolución socialista y su rechazo al reformismo socialdemócrata. Su afinidad con el Amauta revela su interés por desarrollar un pensamiento propio en diálogo con el marxismo y la urgencia de la transformación social, a partir del develamiento de las históricas estructuras y relaciones de poder que invisibilizan los aportes, por ejemplo, de Rosa Luxemburgo, Gramsci y de los revolucionarios no europeos al desarrollo del marxismo (Quijano, 1979), en especial de los que provienen del Ilamado Tercer Mundo, en el que José Carlos Mariátegui ocupa un lugar indiscutible.

Quijano, al igual que Mariátegui, fue un gran lector de la literatura peruana, latinoamericana y mundial y publicó varios artículos referente a ellas. En 1957, publica la antología titulada Los mejores cuentos latinoamericanos. En 1964, "La poesía: una praxis" en Haraui, publicación dirigida por Francisco Carrillo; lo que demuestra su gran interés por la literatura, que no abandonó y la entendió como otra forma de conocimiento, según lo expresa en la revista indicada.

La década de los 50, fueron años de formación teórica, de lectura de los clásicos de la teoría social. En 1962 publica "Wright Mills, conciencia crítica", en 1964 "La imagen saint-simoniana de la sociedad industrial", texto que fue publicado en el primer número de la Revista de Sociología, de la Facultad de Letras de la Universidad Nacional Mayor de San Marcos, que surgió a iniciativa de José Mejía Valera según 
nos relata la profesora Sulema Loayza Alatrista. En ellos asume la visión crítica de la teoría social.

Si el pensamiento crítico marxista no puede ser concebido sólo a través de la retina occidental, es destacable su participación creadora en la teoría de la dependencia. Junto a otros pensadores latinoamericanos inauguró su perspectiva histórico estructural en el cuestionamiento al poder a partir de su reconocimiento de la heterogeneidad histórico estructural de América Latina y la complejidad de las relaciones de poder.

Durante su estadía en Chile fue investigador de la CEPAL. En los años 70 fundó y dirigió la revista Sociedad y Política. Entre 1995 y 1999, junto a Antonio Melis, codirigió el Anuario Mariateguiano. Durante la primera década del siglo XXI integró el colectivo "Modernidad colonialidad" fundado por Walter Mignolo, Alejandro Coronil, Edgardo Lander, Enrique Dussel, Catherine Walsh, Nelson Maldonado-Torres, Santiago Castro Gómez. En los 90 si bien no conformamos un colectivo como tal, Ramón Pajuelo, Marco Mallqui, Jaime Coronado entre otros jóvenes compartíamos eventualmente reflexiones y trabajos con el maestro Quijano. El 2010 fundó y dirigió la "Cátedra América Latina y la Colonialidad del Poder" en la Universidad Ricardo Palma integrada por César Germaná, Julio Mejía Navarrete, Jaime Coronado, Danilo Quijano, Danilo Assis Clímaco, Yuri Gómez y quien escribe, en comunicación con Edgardo Lander, Catherine Walsh, Rita Segato, Alberto Acosta. Fue profesor en diversas universidades del mundo. Sus textos han sido traducidos a una diversidad de lenguas.

\section{III}

\section{La heterogeneidad histórico estructural y la importancia del arte en su obra}

Su relación con la literatura fue muy intensa como lo fue con Arguedas. Se reunían para conversar y discutir con rigurosidad sobre sus indagaciones y propuestas. ${ }^{1}$

Quijano conocía de cerca las condiciones de vida de la población, hablaba quechua, se identificaba plenamente con el paisaje y el territorio, migra a la capital para estudiar y vive las difíciles condiciones de ser migrante y el proceso de cholificación en un país sumamente desigual. Por aquel entonces, consideraba que este proceso sería fundamental en la forja de un país más homogéneo. La lectura de esa

1 Según dio cuenta Carmen María Pinilla, biógrafa de Arguedas, en una conferencia llevada a cabo en junio de 2018. 
mutación es atravesada por su experiencia vital y su formación marxista entre los 50 y los 60, así como por influencia de la teoría crítica, en especial de la Escuela de Frankfurt y su reconocimiento de la razón instrumental planteada por Horkheimer.

En los años sesenta Quijano $(1980,1971)$ se interesó por comprender la "heterogeneidad cultural" que implicaba la convivencia en conflicto de la cultura dominante y la cultura de los dominados, la alternativa era la choledad porque homogeneizaría al país. El tesón, la pujanza, la creatividad y el trabajo de los "cholos" constituían la esperanza.

Consideraba que no existía el liderazgo indio en el movimiento campesino, y si por excepción lo había, estaba en proceso de cholificación.

Entendió la relación entre dominación y cultura, sostuvo que todo universo cultural específico se integra con varios elementos que provienen de diversas instancias históricas y culturas por lo que "es inevitable que la estructura registre heterogeneidades o incongruencias de diverso tipo" (Quijano, 1980:23) que forman una estructura común. Los elementos de un universo cultural global determinado se integran pero no a un mismo nivel en la estructura cultural ya que forman núcleos estructurados que compiten o convergen o se subordinan entre sí.

El cholo podía constituirse en el sujeto de la ansiada transformación social al superar el dualismo entre "modernidad" $y$ "tradición" en tanto portador de valores de cambio podía contribuir a modificar "los elementos de la conciencia campesina tradicional, que estaban en la base de su conformismo, de su actitud apática y fatalista." (Quijano, 1980: 115 ) Esta concepción que formula en Lo cholo y el conflicto cultural en el Perú, la podemos apreciar también en su participación, desde la audiencia, en la Mesa redonda sobre Todas las sangres el 23 de junio de 1965:

Hay una opción indigenista que no me parece, surge esto con tanta claridad, pero el personaje Rendón Willka, es un personaje sumamente equívoco. Yo tuve, al leer la novela, la impresión un poco de que Rendón Willka regresaba totalmente cholificado de la ciudad, y que iba a proceder con suma astucia y maquiavelismo en la conducción política del proceso de insurrección campesina, y que entonces aparecía un poco disfrazado dentro de su propia población pero, la impresión siguiente, sobre todo al final de la novela, es que Rendón Willka se reintegra al marco indígena tradicional. [...] Yo no creo francamente que José María Arguedas postule claramente una solución indígena del problema campesino, que en este momento a todas luces no aparecería viable (Quijano, 1965: p. 60) 
La propuesta indigenizada y no indigenista de José María Arguedas no fue comprendida, con excepción de Escobar, se pensó que correspondía a un pensamiento pasadista.

Rendón Willka encarna en la ficción a un sujeto heterogéneo, que como bien señala Graziela Meneses (2018) actúa según quién sea su interlocutor, no es un sujeto mestizo ni cholo ni indio sin conflictos.

Para Arguedas narrador, la ficción le otorga la posibilidad de recrear a sus personajes con toda la conflictividad y la complejidad que se expresa en sujetos que luchan por su supervivencia cotidiana. Y es sobre todo en El zorro de arriba y el zorro de abajo en donde se configura dolorosamente toda esa confrontación; mientras que en su clásico discurso de 1968: "No soy un aculturado", formula con gran claridad la heterogeneidad territorial y cultural del Perú.

Para Aníbal Quijano (1990a) en los años 60 y 70 del siglo XX, no fueron las ciencias sociales, sino la ficción a través de la narrativa latinoamericana la que tuvo un mayor acercamiento a lo real sobre todo en la obra de Gabriel García Márquez, en tanto habría logrado configurar las imágenes de la resistencia y los distintos tiempos históricos en un mismo tiempo de modo especial en su clásica novela Cien años de soledad que califica como un proceso de reoriginalización cultural, que también se habría dado desde la perspectiva indígena y negra a través de Arguedas en el Perú y Toni Morrison en los Estados Unidos.

En una ocasión al escucharlo comentar sobre su predilección por Cien años ..., le manifesté que al leer Recuerdos del porvenir de Elena Garro sentí una atmósfera muy cercana a la novela de García Márquez, pero que no había tenido la debida promoción, a pesar de haber sido publicada unos años antes. En tanto el tiempo que se rescataba, el tiempo cíclico era semejante al tiempo histórico en las culturas originarias que muchas veces se piensa que es repetitivo y sin asidero, y que esto no parecía ser así, el tiempo cíclico sería similar al de la "Naturaleza" que se renueva siempre de modo análogo al ritmo del cuerpo nuestro, de las mujeres que por ejemplo desde la menarquia hasta su fin parece repetirse cada mes, pero nunca es el mismo. El tiempo cíclico depende de lo que podemos llamar lenguaje histórico corporal y territorial, y que esto pude comprenderlo gracias al testimonio de Asunta Quispe (Ortiz, 2004) registrado y publicado por Carmen Escalante y Ricardo Valderrama (1977).

El tiempo cíclico puede entenderse como círculos concéntricos en movimiento, una dinámica siempre en movimiento en el tiempo. El tiempo moldea el cuerpo y viceversa, la corporalidad es moldeada de dentro hacia afuera y de afuera hacia dentro, en ciclos constantes porque nada permanece estático. Como señala Javier 
Lajo (2016) todo se "'está haciendo', porque nada está quieto, nada esta "siendo", [... ] todo está 'haciéndose y deshaciéndose"', sufriendo una transformación continua.

El concepto de heterogeneidad estructural surge después de la Segunda Guerra, se encuentra en la obra de Raúl Prebisch $(1948,1949)$; mas, es Aníbal Pinto, como bien precisa Quijano, quien ahonda en su configuración y análisis en los años 70.

La heterogeneidad estructural se refiere a la coexistencia en la estructura productiva o a la estructura ocupacional de sectores o actividades de alta productividad por influencia de las tecnologías que se disponen, con otras, que no disponen de alta tecnología y su productividad es baja. Esto que distingue al "centro" de la "periferia", se reproduce en la "periferia", pues hace que exista mano de obra ocupada en condiciones de productividad alta y mano de obra ocupada en condiciones de productividad muy reducida, conformada por el subempleo, por lo demás, muy alto.

Esta visión correspondiente a la teoría estructural de desarrollo continúa vital en la CEPAL en el siglo XXI. Mario Cimoli y Javier Porcile precisan que la heterogeneidad estructural:

\begin{abstract}
que caracteriza a la periferia se define como una situación en la que existen amplias diferencias en los niveles de productividad del trabajo entre sectores de la economía y al interior de cada sector. Estas diferencias son lo suficientemente marcadas como para segmentar claramente el sistema productivo y el mercado de trabajo en capas diversas, en las que las condiciones tecnológicas y de remuneración son fuertemente asimétricas." (Cimoli y Porcile, 2012 :3)
\end{abstract}

Algunas versiones de la idea de heterogeneidad se asociaban y asocian a la de dualismo, que distingue a los trabajadores ocupados en actividades de subsistencia -bien con productividad marginal cero o negativa - y trabajadores empleados en el sector moderno. Cimoli sostiene que aún reconociendo el alto peso de los sectores de subsistencia en la periferia, la heterogeneidad es más que un fenómeno dual, en tanto abarca diversas capas de productividad. Las diferencias de productividad distingue a la periferia de las economías del centro.

Quijano al inicio de los 90 sostuvo que la heterogeneidad estructural supone la coexistencia de patrones estructurales cuyos orígenes y naturaleza eran muy diversos y que el capital constituía el eje de articulación de diferentes, contrapuestas y conflictivas lógicas. Sin embargo, crítico de la perspectiva funcionalista debido a su desinterés de las relaciones históricas de poder, da cuenta de la inoperancia del concepto heterogeneidad estructural si no se tiene en consideración la singularidad histórica. 
El concepto heterogeneidad histórico estructural es configurada a partir de Mariátegui y su reflexión sobre las relaciones sociales y productivas en el proceso de la economía peruana de aquella época. Recordemos que para el Amauta, en los años 20 del siglo pasado, coexistían elementos de tres economías diferentes: la economía feudal, la economía comunista indígena y la economía burguesa bajo el régimen sobre todo de la economía feudal. La lectura de Mariátegui no sigue el evolucionismo europeo.

A fines de los 80 y en el umbral de los 90, Quijano establece a partir de Modernidad y utopía en América Latina una clara ruptura con el eurocentrismo, aunque sus tensiones con este mirar dominante se aprecia desde sus primeras obras. Consideraba que las interrogantes básicas referente a América Latina estaban ausentes. ¿Cómo era la sociedad Latinoamericana en aquel entonces? ¿Cómo era su especificidad? ¿Cómo se ubicaba la estructura global de poder?

Esta ausencia se debía a una atmósfera ideológica que las eludía u ocultaba. La crítica mostraba interés por el funcionamiento del poder, denunciaba sus deficiencias pero no se interesaba por su estructura, sus patrones y fundamentos $y$ menos por las tendencias históricas de cambio, esto ocurría en el mundo y no sólo en América Latina debido en primer lugar a la profunda derrota de los movimientos y grupos sociales; en segundo lugar, por el predominio del eurocentrismo en la reflexión social anclada en el materialismo histórico y positivismo que continuaba clasificando a la sociedad mediante visiones dualistas y evolucionistas concebidas en la relación tradición y modernidad o feudalismo y capitalismo.

En los 90, había una posición en la que se señalaba que este tránsito ya se había cumplido por lo que dejaban de ser categorías significativas y que existía una economía capitalista con sus particularidades de "dependencia", "subdesarrollo" o ubicación "periférica" y por lo tanto la categoría heterogeneidad estructural había dejado de tener importancia. A la sociedad capitalista le correspondía entonces una sociedad burguesa y un Estado burgués por lo que no tenía sentido pensar en la relación entre estado y sociedad, si no entre estado y sociedad civil, cuya noción de ciudadanía se limitaba a la definida por las instituciones del Estado.

Quijano encuentra otra realidad, porque si bien el mercado está mejor posicionado por cuanto los bienes y servicios se han mercantilizado; la fábrica, el salario y el mercado no están poderosamente organizados debido a que la población migrante campesina no se había proletarizado como en la experiencia europea, la descampesinización condujo a la población a la "marginalidad" y a la "informalidad". En América Latina, la desintegración de la servidumbre y sus instituciones 
dio lugar a nuevas tendencias vinculadas a las relaciones mercantiles y una nueva articulación estructural mundial de poder.

En la marginalidad, el mercado se entrelaza con la reciprocidad, la economía de subsistencia, la pequeña producción mercantil simple, el trueque de bienes y servicios. Marginalidad e informalidad se interrelacionan porque no existen o no podrían existir la una sin la otra. Las relaciones sociales de reciprocidad dan lugar en América Latina a instituciones de tendencia comunitaria qué no están presentes en la manufactura fabril, sino en la manufactura artesanal, individual o colectiva y también en la agricultura campesina pero no en el capital agrario.

El mercado existe también valiéndose de la reciprocidad y el dinero camina con el trueque. En los 90 avisora relaciones sociales para esclavistas en los lavaderos de oro amazónicos y en las plantaciones de coca. Ergo, considera que el capitalismo lejos de homogeneizar bloquea los accesos que parecía ofrecer a los que salían de otros patrones estructurales, es en este contexto que surgen nuevos patrones, cuyas tendencias, instituciones y relaciones sociales fueron configurando una nueva heterogeneidad histórico estructural articulada por la estructura y patrón mundial de poder.

Para la comprensión de los patrones estructurales es de suma importancia explorar el modo de existencia del capital en América Latina y las perspectivas generales del capital mundial en el horizonte previsible del futuro. (Quijano, 1990)

Sostiene que el capital en América Latina ha existido históricamente como articulación entre varias modalidades: la acumulación originaria, el capital competitivo, tanto el que se basa en la plusvalía absoluta como el que se sustenta en la plusvalía relativa; el capital monopólico, que se funda en la fuerza de trabajo viva y el trabajo acumulado, y tanto el que está organizado en circuitos nacionales, como el que lo está en circuitos transnacionales. Ninguna de estas modalidades existe sin las otras, pero son dominantes las que ponen en juego formas de acumulación cada vez más intensivas por su tecnología material y organizativa, ninguna constituye una etapa de desarrollo sino que coexisten y combinan, en una estructura global de capital. Su dinámica no es exclusiva sino que está inserta en la estructura mundial del capital, es por tanto capital dependiente. Este patrón estructural constituye la heterogeneidad estructural de América Latina.

Este patrón histórico estructural en América Latina comprende una heterogénea pluralidad de relaciones de producción, que no son solo las relaciones de clase social del capital, dado que en la estructura de poder en la sociedad también están presentes otros "sistemas"; entiende que los agrupamientos sociales se generan en una estructura de poder que no tiene únicamente carácter de clase sino también étnico. 
Precisa que la clase social está definida por un conjunto de "patrones de relación social que producen tendencias de agrupamiento social, no de grupos cerrados, en un proceso de identificación y organización de intereses, que siempre es inacabado y contradictorio, que parten en las relaciones de producción, pero qué se van constituyendo según los patrones que rigen las otras instancias de poder". (Quijano, 1990: 26)

Esas otras instancias de poder está constituida por la revitalización de tendencias de agrupamiento social étnicas que encontró en los trabajos de Silvia Rivera Cusicanqui, Guillermo Bonfil, entre otros.

Con la presión del materialismo histórico que desarrollaba una visión reduccionista de la sociedad al invisibilizar fenómenos como las etnias y el color tan presentes en las relaciones de dominación y explotación, todo el tiempo se buscó clases pertenecientes a patrones estructurales puros o depurados, bien propios del capitalismo o feudalismo; debido a que la teoría de las clases en Europa era básicamente estructural, por lo tanto alejada de toda historia real.

Ante esta situación, encuentra muy esclarecedora la historicidad de las clases de Thompson en lugar de estructuralidad. Por eso en América Latina se acuñó la idea de "estructuralismo histórico". Heterogeneidad histórico estructural, en términos de Quijano, rescata las dos fuentes que encuentra implicada en la teoría de las clases en la obra de Marx y en la obra de Mariátegui, pero también en Thompson.

Por eso, considera pertinente replantear e indagar los vínculos entre las relaciones de producción y los patrones de agrupamiento social en su dimensión étnica. Por otro lado, las relaciones entre las varias instancias de la sociedad entre sí y las implicaciones de esas relaciones sobre la totalidad. Se interroga, si las clases están vinculadas a relaciones de producción o de explotación a qué lo estarían las "etnias". Consideraciones que irá aclarando cuando, desde 1991, empieza a acuñar la perspectiva teórica de la colonialidad del poder.

Si el estado se constituye como una relación de clases y si la sociedad se organiza más entre etnias que clases, qué papel y lugar juegan las etnias en la relación Estado-sociedad, en las relaciones de clase y la multiinserción social, son interrogantes que formula en el proceso de acuñar la perspectiva naciente.

Cuestiona además la visión lineal entre la economía, la sociedad, la cultura y la política, entendiendo que el universo intersubjetivo y cultural abarca una prolongada historia que atraviesa varios patrones de poder por lo que las relaciones entre ese universo y la estructura no son lineales.

Otro factor que influye en su visión crítica y descolonialidad está constituido por los movimientos sociales en los años 60 , sobre todo los llevados a cabo por los 
jóvenes en Shanghái en 1967, en París y Tlatelolco en 1968, en Praga y los Estados Unidos en 1969, en la subversiva fiesta de Woodstock, los cuales configuran a decir de nuestro autor un "horizonte de futuro", es decir, "un imaginario crítico más radical y más global, que se enfrentaba al capitalismo y al despotismo burocrático del "socialismo real", al mismo tiempo." (Quijano, 2014, p. 842)

Se configura "un imaginario asociado a la liberación de las gentes del poder, de todo poder. Y como es normal en la historia, fueron la música, las artes visuales, la poesía y el relato las formas de expresión más ceñidas del nuevo imaginario". (Quijano, 2014, p. 842)

En cambio, en los 80 , se consumó la derrota, el descalabro de la modernidad, de la racionalidad del progreso sin fin anunciado por el liberalismo, el nacionalismo y el socialismo, que se sintió a partir de la caída del muro de Berlín, de la desintegración del "campo socialista" o del socialismo realmente existente, de la crisis global del capitalismo, de la crisis de paradigmas. Comprendió la urgente y necesaria ruptura con el eurocentrismo, había que desaprender y retornó a la fuente primordial, su experiencia vital en diálogo con los saberes invisibilizados, lo que da cuenta con mayor intensidad de sus desencuentros con el marxismo eurocéntrico.

Es allí donde vuelve a la literatura y a Mariátegui, encuentra un proceso de reoriginalización cultural, en el El zorro de arriba y el zorro de abajo de Arguedas y en The Song of Solomon de la gran Toni Morrison, por cuanto configuran significados y epistemes originales, probablemente por ser Perú y los Estados Unidos los dos territorios más antiguos del dominio colonial y de la migración. En Arguedas se expresa el entrelazamiento entre la utopía de la liberación social y la de la identidad. Y es que para Quijano (1990a) la transformación del mundo tiene lugar primero como transfiguración estética, por lo que habría una relación fundamental entre utopía y estética.

Paralelamente surgen tres textos suyos muy significativos Modernidad, identidad y utopía en América Latina (1988); "Colonialidad y modernidad-racionalidad" (1991), "La nueva heterogeneidad cultural de América Latina" (1990), textos fundamentales en la gestación de la colonialidad del poder.

En los 90 se reencuentra con Yanama, los movimientos indígenas y desarrolla y fortalece su visión referente a la "heterogeneidad histórico estructural"y empieza a formular la perspectiva teórica de la colonialidad del poder. Es así que vuelve a las huellas marcadas por la cordillera de los Andes y a las estelas dejadas por Arguedas. Se reencuentra críticamente con los orígenes, con el episteme negado pero abierto siempre a lo diverso. La colonialidad del poder emerge de esa ruptura. 
El "campesinado", como pensaba Marx y el marxismo eurocéntrico, no fue más un "costal de patatas".

Para Quijano, la música, la poesía, las artes visuales, el relato — a diferencia de las ciencias sociales-, están más cercanas a comprender el imaginario social y por eso son capaces de sentir y anunciar el nuevo imaginario que empezó a emerger a partir de los años 90. Quijano, en su estancia boricua encuentra un factor vital más para comprender la relación entre poder y cuerpo en el que nos jugamos la vida. Comprende que el ritmo, la música, el baile constituyen espacios-tiempo de confrontación en el que el cuerpo a través del arte se libera de la prisión eurocentrista de la dualidad materia-espíritu, cuerpo-mente, emoción-razón. Comprendo su inquietud cuando conversábamos sobre la importancia del cuerpo en la expresión literaria y artística de las mujeres.

Al comenzar el siglo, su visión es optimista, pareciera que surge un nuevo imaginario que sugiere el regreso del futuro, el regreso de la esperanza. (Quijano, 2001).

A propósito de mi estadía en Quito entre 1995 y 1997, que coincidió con las excepcionales movilizaciones indígenas, rememoro la conversación que entablamos en aquellos años sobre tal acontecimiento, le manifesté mi interés por escuchar, aprender, dialogar y comprender las nuevas voces en la escena pública de modo directo, sin intermediarios; sobre todo de las y los intelectuales kichwas que surgieron a fines de los 80 e inicios de los 90, en particular en Otavalo, Ecuador y sobre las subjetividades y literaturas afroindígenas que finalmente constituyeron las áreas de trabajo en mis estudios de posgrado.

Este nuevo imaginario se incuba desde los 80 en las expresiones y movimientos culturales y artísticos indígenas en América Latina al cumplirse en 1992, el V centenario del violento encuentro; pero también en la población afrocaribeñolatinoamericana. No es solo la lucha identitaria lo que los moviliza sino la exigencia de la radical redistribución del poder y por lo tanto el cuestionamiento del racismo.

Es este cuestionamiento al poder lo que llamó la atención a Quijano, en tanto es fundamental en la organización y transformación social y por eso un factor primordial en su obra. Uno de las dimensiones del poder es la colonialidad que comprende la idea de raza y el eurocentrismo, ambos fundamentales para explorar y comprender las relaciones y estructuras históricas del patrón global de poder en los diferentes ámbitos de la vida social.

El racismo, como da cuenta Quijano, se ha construido sobre la idea de raza que no tiene fundamento real alguno. Es estrictamente un invento que surge en el momento en que comienza la violencia de la conquista y rápidamente se convirtió 
en una forma de relación social que racializó todos los ámbitos de la vida social: el mundo del trabajo, la autoridad, la subjetividad.

Las repúblicas en los Andes se han construido a partir de la impostura de la idea de raza, es decir a partir del racismo. No solo porque gobiernan criollos o "blancos" o "ablancados" sino porque las leyes y el orden social en su conjunto los protegen en todos los ámbitos, de la vida social.

Quijano aprendió y se mostró presto a escuchar y a dialogar con los movimientos y la producción intelectual de las mujeres y feministas, y los movimientos indígenas, lo que le permitió incorporar la dimensión sexo-género y "Naturaleza", pero considerando que la idea de raza es uno de los principales componentes del patrón global de poder.

Mas, siendo el poder un haz de relaciones de estructuración histórica biosocietal, la idea de raza y la racialidad es un componente ineludible del patrón global de poder, pero como lo hemos señalado en otras ocasiones, es necesario precisar que no es el único, como tampoco lo es solo el poder económico definido a través de la relación capital/Naturaleza/trabajo en términos de "clases sociales", en tanto no habrían existido aislados del patriarcado como relación de dominación y organización social, sexual y simbólico de larguísima duración en Occidente, cuya violencia comandó los procesos coloniales y se ha mantenido reinventándose durante la formación de la república hasta hoy.

\section{Conclusiones preliminares}

Ante la crisis raigal del patrón global de poder, pese a su aún real hegemonía ¿qué hacer?

Para Quijano es fundamental interrogarse sobre nuestra América, territorio en donde se expresan y configuran espacios y tiempos diversos, histórica, social y territorialmente heterogéneos, articulados por esa hidra del patrón global de poder.

Mas, ¿qué preguntar? ¿Desde dónde preguntar?

Si se aprende a escuchar las demandas y sentires de la población y los movimientos de la sociedad y si comprendemos que somos cosmos, psique, cuerpo, territorio, sociedad, historia, se comprenderá que expresan la complejidad de esa heterogeneidad.

El problema radica en que cada sector parece apuntar a una sola dimensión del poder, olvidando que el poder está constituido por un haz de relaciones sociales que constituyen una totalidad profunda e históricamente heterogénea e 
interdependiente. El patriarcado constituye uno de sus componentes que atraviesa y es atravesado por cada una de esas relaciones, si se pone en cuestión una sola dimensión vinculada a la relación capital trabajo o a la racialidad o el género, o un solo aspecto, asociado a lo estrictamente normativo sujetas a la determinación de un Estado y capitalismo patriarcales convertidos en Leviatán cambiará sólo la apariencia y continuará la historia de violencia y opresión, y será muy poco lo que se logre para el bienestar de las mayorías. La categoría heterogeneidad histórico estructural y cultural permite aproximarnos y comprender esa complejidad.

Su estadía en variopintas regiones del mundo como parte de su experiencia primordial, entre ellos el boricua, los puentes entre la academia y los movimientos sociales, como lo fue con el movimiento obrero y barrial en los 60 y 70, su acompañamiento al Foro Social Mundial —llevado a cabo en diversas latitudes- y a los movimientos indígenas del siglo XX y siglo XXI, su interés por dialogar con la reflexión de las mujeres y feminismos constituyen algunas de las fuentes principales de su reflexión y producción intelectual. Esta perspectiva de aprendizaje dialógico, que no fue fácil, le permitió acercarse con mejores herramientas para explorar y comprender la heterogeneidad histórico estructural y cultural del Perú, las relaciones y patrones globales de poder y los horizontes de sentido que se gestan en nuestra América/Abya Yala que hacen de Quijano, parafraseando al poeta Hildebrando Pérez cuando se refiere a nuestro querido César Vallejo, un "aldeano universal" o, se podría señalar que forma parte de esa gama de peruanas/os e indoafroamericanas/ os pluriversales, entre ellos Felipe Guaman Poma, José Carlos Mariátegui, Victoria y Nicomedes Santa Cruz, José María Arguedas, Blanca Varela.

\section{Obras citadas}

ARroyo, E. (2017). “Eduardo Arroyo entrevista a Aníbal Quijano”. Lima: Universidad Ricardo Palma. Recuperado http://www.urp.edu.pe/urp/pdf/anibal_quijano.pdf

Assis CLímACO, D. (2014). Aníbal Quijano: Cuestiones y horizontes. Antología esencial. De la dependencia histórico estructural a la colonialidad / descolonialidad del poder, prólogo de D. Assis Clímaco, Buenos Aires, CLACSO.

Carrillo, F. (1964). Haraui. Año 1, № 2, Lima, Perú.

CHAMBERS, I. 1994(). Migración, cultura, identidad. Buenos Aires: Amorrortu Editores.

CIMOLI, M; PORCILE, G. ( 2012). Tecnología, heterogeneidad y crecimiento: una caja de herramientas estructuralista, en Heterogeneidad estructural | Raúl Prebisch y los desafíos del Siglo XXI, CEPAL, https://biblioguias.cepal.org/ld.php?content_id=30425075 
LAJO, J. (2016). "Pacha y paqha: tiempo y espacio en la filosofía andina”. En América Latina en movimiento, 24.06.2016. https://www.alainet.org/es/articulo/178353

MARIÁTEGUI, JC. (1995). 7 ensayos de interpretación de la realidad peruana. Lima: Amauta.

MENESES DE JESÚS, G. (2018). "Todas las sangres y el debate sobre el mestizo peruano", Rompiendo la jaula de la dominación. Ensayos en torno a la obra de Aníbal Quijano. Santiago de Chile: Editorial Doble Ciencia Limitada.

ORTIZ FeRnÁNDEZ, C. (1993). Clorinda Mato de Turner. La censura y la fe. Modernidad, etnicidad y género. Tesis. Lima: Facultad de Ciencias Sociales de la Universidad Nacional Mayor de San Marcos.

ORTIZ FERNÁNDEZ, C. (1999). La letra y los cuerpos subyugados. Heterogeneidad, colonialidad y subalternidad en cuatro novelas latinoamericanas. Quito: Universidad Andina Simón Bolívar.

OrTiZ FERnÁNDEZ, C. (2004). Procesos de descolonización del imaginario y del conocimiento en América Latina. Lima: Fondo Editorial Facultad de Ciencias Sociales, UNMSM.

ORTIZ FernándeZ, C. (2018). “Aníbal Quijano. Yanama, Perú 1928-Lima, Perú 2018", Pluriversidad Año 1, №1. Lima: Universidad Ricardo Palma.

PINILLA, C. (2018). Vida y obra de Aníbal Quijano (Homenaje). Lima: PUCP, 19 de junio de 2018.

QuIJANO, A. (1954). Los mejores cuentos latinoamericanos. Selección de Aníbal Quijano. Lima: Juan Mejía Baca \& P. L. Villanueva Editores.

QuiJano, A. (1962). “Wright Mills, conciencia crítica”. En Revista Nacional de Cultura. Tomo XXXI, pp. 305-313. Lima, Perú.

QuIJANO, A. (1964). "La imagen saint-simoniana de la sociedad industrial". En Revista de Sociología, Volumen 1, julio-diciembre. Número 1. Lima: Departamento de Sociología, Facultad de Letras, Universidad Nacional Mayor de San Marcos.

QuiJano, A. (1964). “La poesía: una praxis". En Haraui. Año 1, № 2, Lima, Perú.

QUIJANO, A. (1979). "Prólogo", 7 ensayos de interpretación de la realidad peruana. Caracas: Biblioteca Ayacucho.

QuiJano, A. (1980). Dominación y cultura. Lo cholo y el conflicto cultural en el Perú. Lima: Mosca Azul Editores.

QuIJANO, A. (1990).“La nueva heterogeneidad cultural de América Latina”, en Hueso húmero, No 26. Lima: Mosca Azul/ Campodónico editores.

QuiJAno, A. (1990a). “Estética de la utopía”. En Hueso húmero, № 27, 32-42. Lima.

QuIJANO, A. (1991). “Colonialidad y modernidad-racionalidad", en Perú Indígena № 29. México: Instituto Indigenista Peruano e Interamericano.

QuIJANO, A. (1999). “Prólogo", en Carolina Ortiz, La letra y los cuerpos subyugados. Heterogeneidad, colonia lidad y subalternidad en cuatro novelas latinoamericanas. Quito, Universidad Andina Simón Bolívar. 
QuiJano, A. (2014). "José Carlos Mariátegui: reencuentro y debate." Prólogo a 7 ensayos de interpretación de la realidad peruana, en Aníbal Quijano: Cuestiones y horizontes. Antología esencial. De la dependencia histórico estructural a la colonialidad/descolonialidad del poder, selección y prólogo de Danilo Assis Clímaco, Buenos Aires, CLACSO [1979] . QuIJANO, A. (2001). "El regreso del futuro y las cuestiones del conocimiento". En Hueso húmero, №38, abril. Lima.

Carolina Ortiz Fernández. Licenciada en Sociología por la Universidad Nacional Mayor de San Marcos. Magíster en Género, identidad y ciudadanía por la Universidad de Huelva, España. Magíster en Letras por la Universidad Andina Simón Bolivar de Quito. Doctora en Ciencias Sociales por la Universidad Nacional Mayor de San Marcos. Docente del Departamento Académico de Sociología de la Universidad Nacional Mayor de San Marcos. Correo electrónico: cortizf@unmsm.edu.pe

Recibido: febrero 2019

Aprobado: mayo 2019 